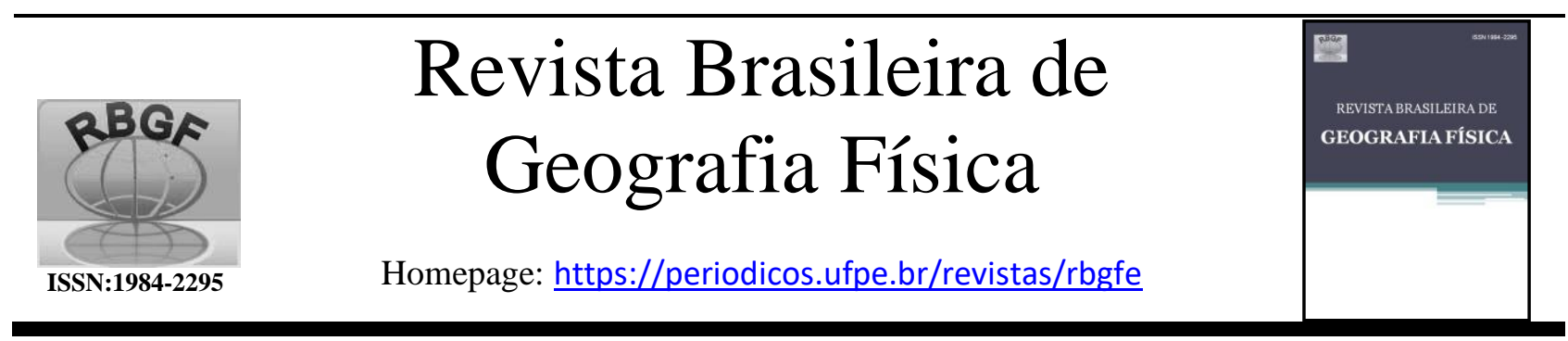

\title{
Condições Climáticas e Meteorológicas Associadas aos Desastres Naturais em São Luiz do Paraitinga - SP: análise dos verões de 1982 a 2014
}

\author{
Isabela Taici Lopes Gonçalves Horta ${ }^{1}$, Gustavo Zen de Figueiredo Neves ${ }^{2}$
}

\begin{abstract}
1Universidade de São Paulo (USP), São Carlos, São Paulo, Brasil. E-mail: isa.horta@usp.br (autora correspondente).
${ }^{2}$ Universidade de São Paulo (USP), São Carlos, São Paulo, Brasil.
\end{abstract}

Artigo recebido em 26/07/2019 e aceito em 24/10/2019

\section{R E S UMO}

O estudo aqui apresentado teve como objetivo descrever as condições climáticas e meteorológicas que favoreceram a ocorrência de desastres e os respectivos danos causados pelos impactos no município de São Luiz do Paraitinga - SP, na ocorrência de nove eventos desastrosos deflagrados por chuvas. Localizado no Vale do Paraíba, o município tem um clima que se caracteriza por elevada pluviosidade, geneticamente relacionado ao litoral norte do estado de São Paulo. Sua geomorfologia é determinada pela ação das chuvas abundantes e pela alta amplitude térmica. O resultado das características climáticas e geomorfológicas é o constante extravazamento do rio Paraitinga, causando inundações constantes no município. Para análise da problemática foi realizada uma consulta ao Banco de Desastres do IPMet Centro de Meteorologia de Bauru que possibilitou as informações detalhadas sobre os desastres ocorridos., foi utilizado os Boletins Climanálise e os dados de pluviometria do banco de dados Hidroweb. A partir da estatística descritiva foi possível verificar que os eventos desastrosos foram deflagrados por chuvas que estavam, na maioria das vezes, acima da média ou média referente à escala temporal analisada (verões de 1982 a 2014), destaca-se que esses valores altos de precipitação são considerados recorrentes para o período analisado. Quanto aos sistemas atmosféricos, tem-se que as chuvas fortes foram formadas no domínio da ZCAS em atuação conjunta com os VCANs e a Alta da Bolívia, comportamento já observado na literatura há tempo. Os apontamentos realizados no presente estudo podem embasar políticas de prevenção a desastres naturais do tipo inundação.

Palavras-chave: Climatologia, Precipitação, Inundação, Desastres Naturais, Seguridade Social.

\section{Climate and Meteorological Conditions Associated With Natural Disasters in São Luiz do Paraitinga municipality, Brazil: analysis of summers from 1982 to 2014}

\begin{abstract}
A B S T R A C T
The present study aimed to describe the climatic and meteorological conditions that favors the occurrence of disasters and the respective damages caused by the impacts in the municipality of São Luiz do Paraitinga - SP, in the occurrence of nine disastrous events triggered by rainfall. Located in the Paraíba Valley, the municipality has a climate characterized by high rainfall, genetically related to the northern coast of the state of São Paulo. Its geomorphology is determined by the action of abundant rains and the high thermal amplitude. The result of the climatic and geomorphological characteristics is the constant extravasation of the river Paraitinga, causing constant floods in the municipality. In order to analyze the problem, the consultation was carried out with the Disaster Database of the IPMet - Bauru Meteorological Center, which enabled the detailed information on the disasters that occurred, using the Climanálise Bulletins and the pluviometric data of the Hydroweb database. From the descriptive statistics it was possible to verify that the disastrous events were triggered by rains that were, more often than not, above the average or relative to the time scale analyzed (summers from 1982 to 2014), it is noted that these high values of precipitation are considered recurrent for the period analyzed. As for the atmospheric systems, it has been observed that heavy rains were formed in the domain of south atlantic convergence zone (SACZ) in conjunction with the high level cyclonic vortex (HLCV) and Alta of Bolivia, a behavior already observed in the literature for some time. The notes made in the present study may support flood prevention natural disaster prevention policies.
\end{abstract}

Keywords: Climatology, Precipitation, Flood, Natural Disasters, Social Security. 


\section{Introdução}

\section{A problemática}

Situações calamitosas como aquelas ocasionadas por desastres naturais apresentam uma complexidade em todos os âmbitos, desde sua ocorrência até a fase de recuperação dos danos. Os fatores condicionantes para tais situações são tanto sociais como ambientais, no entanto os Desastres Naturais têm como fator inicial o fenômeno natural adverso.

A adaptação aos fatores climáticos é condição básica para a sobrevivência dos seres vivos na Terra. No entanto, tornar-se resiliente às adversidades climáticas é essencial não só para a sobrevivência, mas para o desenvolvimento da sociedade.

A sociedade brasileira, por sua vez, tem que lidar, especificamente, com as adversidades climáticas e hidrológicas relativas ao excesso ou à falta de chuva. É demonstrado na Tabela 1 dados referentes a um período de 70 anos (de 1948 a 2018) no Brasil, o desastre mais frequente no país foi do tipo "Inundação", sendo esse, o segundo desastre mais oneroso. Já o desastre que mais prejudica a economia do país é do tipo "Seca", e se coloca como a quarta maior ocorrência.

Tabela 1. Tipo, ocorrência e prejuízo dos desastres Naturais no Brasil (1948 a maio de 2018).

\begin{tabular}{ccc}
\hline Tipo de Desastre & Ocorrência & Total de prejuízo ('000 US\$) \\
\hline Inundação & 134 & 9.422 .254 \\
\hline Desmoronamento & 24 & 231.027 \\
\hline Tempestade & 19 & 533.000 \\
\hline Seca & 18 & 11.183 .100 \\
\hline Epidemias & 18 & sem dados \\
\hline Temperaturas extremas & 8 & 1.075 .000 \\
\hline Incêndios & 3 & 36.000 \\
\hline Terremoto & 2 & 5.000 \\
\hline Infestação de Insetos & 1 & sem dados \\
\hline
\end{tabular}

Fonte: The International Disaster Database. Centre for Research on the Epidemiology of Disasters (EMDAT).Organizado pelos autores.

Em termos de Gestão do Desastre no Brasil, o primeiro nível gerencial é o município. Seja nos momentos anteriores à situação calamitosa, durante ou após são as instituições municipais que devem se prontificar para atuar na prevenção e mitigação dos danos.

A análise realizada no presente estudo teve como objetivo descrever as condições climáticas e meteorológicas que favoreceram a ocorrência de desastres e os respectivos danos causados pelos impactos no município de São Luiz do Paraitinga SP que segue a mesma tendência do país, tendo como o desastre de maior ocorrência do tipo "inundações".

O município de São Luiz do Paraitinga SP, localizado na parte leste do estado de São Paulo, carrega fatores históricos, geomorfológicos e climáticos que acabam propiciando a ocorrência de desastres como inundações e desabamentos, e acabam afetando todos os setores do município (Horta, 2017). A inundação que ocorreu na passagem do ano de 2009 para 2010, por exemplo, representou um prejuízo de $\mathrm{R} \$ 103,63$ milhões para o município (Corsi, Azevedo e Gramani, 2012).

Breve revisão dos conceitos
O desastre em si, é a consequência calamitosa após o impacto de um fenômeno adverso, em decorrência de uma condição em que a sociedade afetada se encontrava naquele momento. Na medida em que se executam ações para melhorar tais condições, pode-se até mesmo, evitar o desastre.

O desastre natural é um evento que resulta da interrupção do funcionamento normal de uma comunidade, seja de ordem econômica, danos ambientais e à saúde humana. $\mathrm{O}$ desastre afeta a capacidade da sociedade em lidar com a situação utilizando os seus próprios recursos (Eird, 2004; Opas, 2015, p. 9).

De acordo com Kronet al, (2012), um desastre não se realiza sem que haja ameaças, que se relacionam à qualidade dos eventos físicos que podem ser gerados pela dinâmica da natureza. Tais ameaças estão amplamente organizadas em diversas bases de dados internacionais sobre desastres naturais, como Center for Research on the Epidemiology of Disasters (CRED) e outros, sendo: eventos geológicos e geofísicos: estão relacionados aos processos erosivos, movimentos de massa e deslizamentos, processos geotécnicos; eventos meteorológicos: envolvem fenômenos 
como raios, tornados, rajadas de vento e outros; eventos hidrológicos: processos resultantes de alagamentos, inundações, enchentes e movimentos de massa úmida; eventos climáticos: estão relacionados à estiagem e seca, geadas, ondas extremas de frio e de calor.

Tais eventos possuem qualidades específicas por sua intensidade, duração, probabilidade, frequência, magnitude e localização geográfica. São ações combinadas, individuais ou sequenciais que precisam, necessariamente, ser intermediadas pela população para que se convertam em ameaça, seja pela exposição, como também a vulnerabilidade da comunidade (Narváres et al, 2009).

Para evitar o desastre é preciso entender todas as variantes e funções de um evento calamitoso. Os atores empenhados nessa temática, tais como a Defesa Civil e a Academia somam esforços para que tais fatores e variáveis sejam cada vez melhor definidas.
Relacionados entre si, os conceitos de risco, perigo, desastre e vulnerabilidade são definidos como uma causalidade de eventos. A preocupação do ser humano se inicia quando os fenômenos naturais ocorrem ou se deslocam em direção a um sistema social. Essa seria uma situação de perigo (Marcelino, 2008).

$\mathrm{Na}$ situação de perigo existem duas possibilidades de sucessão. Uma delas seria esse evento causar impactos de difícil superação para a sociedade afetada e, a outra, seria causar impactos mínimos ou nulos. Na ocorrência da primeira possibilidade, está estabelecido o desastre. $\mathrm{Na}$ ocorrência da segunda, tem-se apenas o evento natural (Marcelino, 2008). Na Figura 1 são ilustradas tais possibilidades, em que na Figura 1A a intersecção entre sistemas humanos e os eventos extremos em potencial gera um perigo para a população humana e, na Figura 1-B a intersecção ente eventos extremos corrente geram o desastre para a população humana.

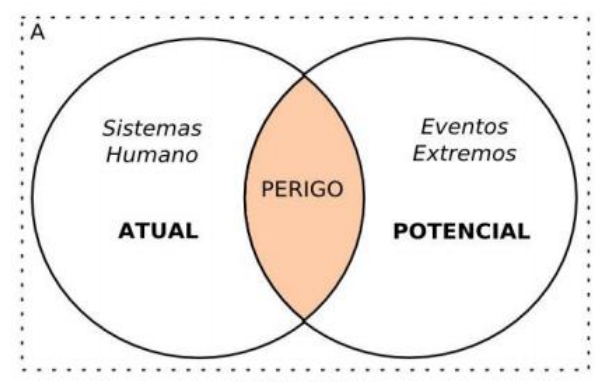

RISCO

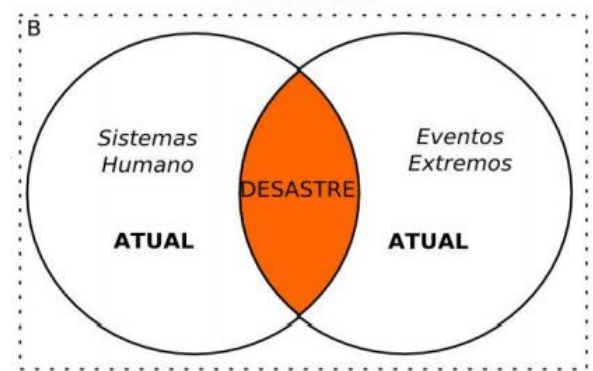

Figura 1. Definição esquemática sobre Risco, Perigo e Desastre.

Fonte: Marcelino, 2008.

A Secretaria de Defesa Civil define desastre como o resultado de eventos adversos, naturais ou provocados pelo homem, sobre um ecossistema vulnerável, causando perdas humanas, materiais e ambientais e consequentes prejuízos econômicos e sociais. Sua intensidade depende, ainda, da interação entre a magnitude do evento adverso e a vulnerabilidade do sistema, sendo quantificada em função de danos e prejuízos (CEPED, 2012).

A sistematização das informações como danos, quantidade de vítimas, abrangência do impacto, entre outras, é necessária tanto para fundamentar os pedidos de auxílio às seguradoras Horta, I.T.L.G., Neves, G Z. de F. ou às entidades governamentais, quanto para embasar estudos posteriores sobre o desastre ocorrido.

Nesse sentido, o município de São Luiz do Paraitinga, conta com os registros do Banco de Desastres Naturais, do IPMet - Centro de Meteorologia da UNESP de Bauru. Esse banco de dados reúne registros dos eventos calamitosos desde 1967 até os dias atuais e fornece informações sobre a data dos eventos, a cidade, as coordenadas geográficas, o código de Classificação e Codificação Brasileira de Desastres (COBRADE), o tipo de fenômeno, o dano causado e a fonte do registro. 


\section{Aspecto Climático}

No que diz respeito ao aspecto climático, Monteiro (1991) nos lembra que, a dinâmica atmosférica apresenta certo ritmo que se manifesta numa sucessão habitual dos tipos de tempo. No entanto, além da tendência existem aqueles eventos excepcionais, os quais embora esporádicos são os que verdadeiramente impactam a vida no planeta, uma vez que a população não esteja preparada para tais.

Eventos extremos são aqueles que, em termos meteorológicos ou climáticos, apresentam grandes desvios da média e podem ocorrer com uma frequência de dias ou milênios. Uma das formas de compreender a variabilidade, a tendência e os desvios climáticos de determinada região é por meio de medidas de estatística descritiva sobre os valores a serem analisados, tais como os valores de precipitação (Monteiro, 1991; Boin e Zavattini, 2013).

Considerando que os desastres no Brasil ocorrem por causas climáticas e hidrológicas, é importante compreender os processos atmosféricos e seus reflexos na sociedade. O Boletim Climanálise, do Instituto Nacional de Pesquisas Espaciais (INPE), disponibiliza em suas edições mensais um relatório descritivo sobre os sistemas atmosféricos em atuação nos diferentes níveis da camada atmosférica.

\section{Objetivo}

O presente estudo teve como objetivo investigar e descrever o contexto climático e meteorológico dos desastres decorrentes de chuvas no município de São Luiz do Paraitinga - SP e os consequentes danos para o município.

Com isso, espera-se colaborar para o entendimento dessa problemática e disponibilizar conteúdo para políticas, planos e projetos que visem à estruturação de sociedades mais resilientes aos eventos de precipitação.

\section{Metodologia}

Utilizou-se uma metodologia baseada nos princípios da análise sistêmica para, então, compreender os sistemas atmosféricos associados aos desastres estudados.

\section{Caracterização da área de estudo:}

O município de São Luiz do Paraitinga SP está localizado na parte sudeste do estado de São Paulo, nas coordenadas $23^{\circ} 13^{\prime} 23^{\prime \prime}$ Sul e $45^{\circ}$ $18^{\prime} 38^{\prime \prime}$ Oeste. Têm-se registros das primeiras atividades econômicas nessa região desde o século XVII, porém foi só no século XVIII que o povoado foi fundado oficialmente.

Inicialmente, no século XVIII a principal atividade econômica era a agricultura de subsistência. Já no século seguinte, a monocultura cafeeira e a produção de cereais foi o que moveu a economia local, foi nesse momento também que ocorreu um crescimento populacional no município.

No século XX, com declínio do escoamento do café, a população luizense acabou migrando principalmente para a capital paulista e, a atividade econômica em São Luiz passou a se caracterizar pela policultura e a produção leiteira. Atualmente, a atividade econômica predominante é a plantação do eucalipto e o turismo.

Característico de áreas tropicais, a geomorfologia de São Luiz do Paraitinga é determinada pela ação das chuvas abundantes e pela alta amplitude térmica, que propicia a atuação do intemperismo físico e químico sobre as rochas da região. $\mathrm{O}$ resultado é o relevo com vertentes suavemente arredondadas, denominado por Ab'Sáber (1966 apud Moura; Jimenez-Rueda; Martins-Coelho, 2006) de "domínio de mares de morros".

É importante destacar ainda que o município faz parte da região do Vale do Paraíba, tendo em sua hidrografia o Rio Paraitinga e o Rio Paraibuna que, quando se unem, formam o Rio Paraíba do Sul, um dos mais importantes para o abastecimento da Região Sudeste do Brasil.

O clima do município caracteriza-se por elevada pluviosidade, geneticamente relacionado ao litoral norte do estado de São Paulo, sazonalmente controlado pelos sistemas equatoriais e tropicais e, por vezes pelas frentes Polar Atlântica, Polar Atlântica Estacionária e Polar Atlântica em Dissipação (INSTITUTO FLORESTAL, 2006; Sant'anna Neto, 1990).

Destaca-se a atuação da Zona de Convergência do Atlântico Sul relacionado ao Sistema de Monção da América do Sul como um dos principais sistemas produtores de chuva na região. A atuação desses sistemas ocorre principalmente durante os meses mais chuvosos relativos à primavera e verão (Ganet al., 2004 apud Quadro; Pezzi; Rosa, 2006).

Na Figura 3 é mostrada a localização das estações utilizadas para o estudo, bem como o limite municipal de São Luiz do Paraitinga e sua drenagem principal. 


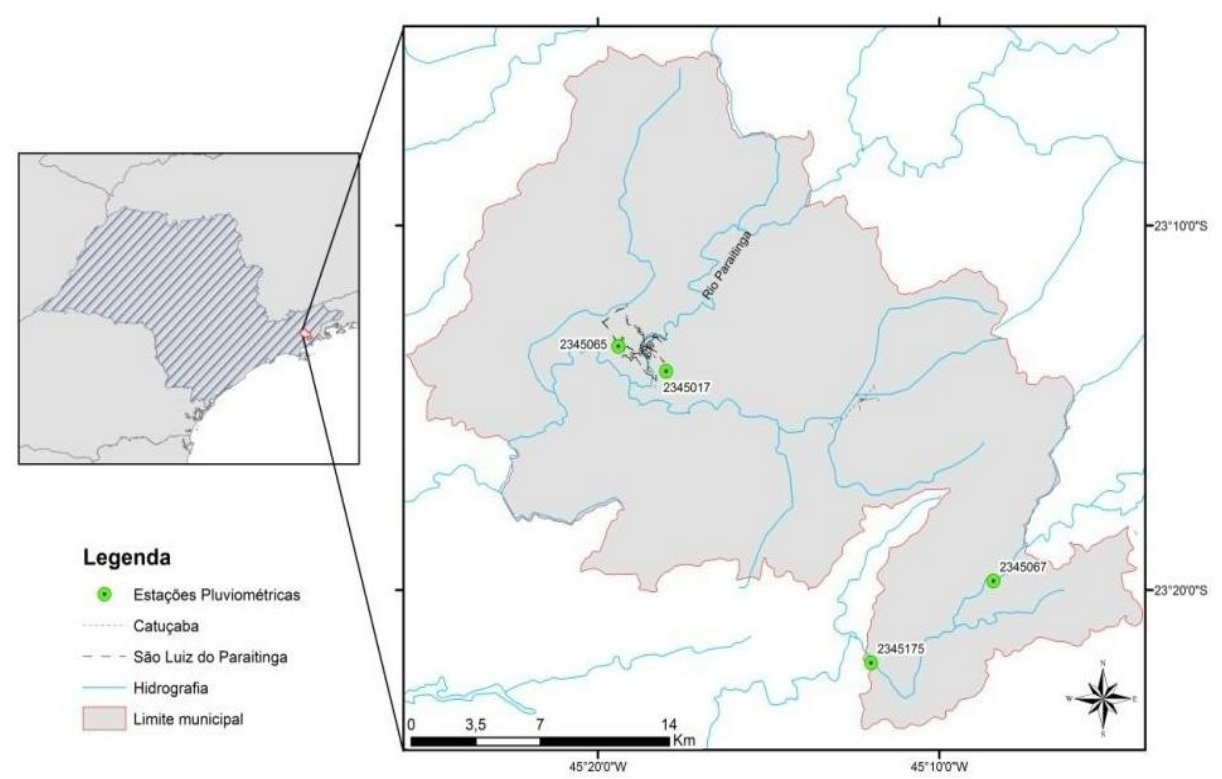

Figura 2. Localização de São Luiz do Paraitinga e das estações pluviométricas utilizadas.

\section{Escala temporal}

A escala temporal analisada compreendeu o período de 1982 a 2014, sendo agrupados e selecionados os meses correspondentes ao período de verão (dezembro, janeiro, fevereiro). Esse ínterim foi escolhido em decorrência dos seguintes requisitos:

- Período de 30 anos ou mais para análises climatológicas, de acordo com a Organização Meteorológica Mundial (OMM);

- Região com chuvas concentradas nos meses de dezembro, janeiro e fevereiro, de acordo com o Instituto Nacional de Pesquisas Espaciais (INPE);

- Disponibilidade de registros de Desastres Naturais no Banco de Dados de Desastres Naturais do IPMet;

- Disponibilidade de registros de precipitação na base de dados online Hidroweb;

\section{Materiais}

Os dados necessários para análise foram extraídos das seguintes fontes:

- Banco de Desastres Naturais, do IPMet Centro de Meteorologia de Bauru;

- Boletim Climanálise;

- Plataforma Hidroweb, da Agência Nacional de Águas (ANA).

Os critérios utilizados para a consulta ao Banco de Dados de Desastres Naturais foram: 01/01/1982 para o campo "Data Início", 31/12/2014 para o campo "Data Fim", todos para o campo "Fenômeno", São Paulo para o campo "Estado", Paraitinga para o campo "Cidade".

A fim de se obter apenas as ocorrências referentes ao período do verão, foram descartados os registros que não correspondiam aos meses de Dezembro, Janeiro e Fevereiro.

A partir da data do registro da ocorrência obtida pelos dados do Banco de Dados de Desastres Naturais, foi possível, selecionar os Boletins Climanálise para a identificação e descrição dos sistemas atmosféricos associados aos eventos calamitosos.

Foram utilizados as seguintes edições do Boletim Climanálise: Fevereiro de 2004, Janeiro de 2005, Fevereiro de 2006, Janeiro de 2007, Janeiro de 2008, Fevereiro de 2009, Dezembro de 2009, Janeiro de 2010, Dezembro de 2010, Janeiro de 2011, Janeiro 2013.

Sobre os dados de precipitação utilizados para embasar a análise estatística, esses foram obtidos pelos registros das Estações Pluviométricas convencionais disponíveis na plataforma Hidroweb da ANA.

Existem no limite do município de São Luiz do Paraitinga, 12 estações pluviométricas (ANA, 2009). No entanto, foram utilizados apenas os dados daquelas que contém valores de precipitação referente aos meses de dezembro, janeiro e fevereiro e, que foi possível corrigir as falhas encontradas na série.

Dessa forma, apenas quatro estações atenderam a esse requisito, foram aquelas denominadas com os códigos da ANA: 02345065, 02345017, 02345175 e 02345067. Na Tabela 1 são apresentados mais detalhes sobre as estações: 
Tabela 2. Estações Pluviométricas utilizadas. Fonte: Agência Nacional de Águas, Brasil (ANA, 2009).

\begin{tabular}{ccccc}
\hline Código da Estação & Início da coleta & Fim da coleta & Órgão Responsável & Presença de falhas \\
\hline 2345065 & $01 / 08 / 1930$ & não consta & ANA & Não \\
\hline 2345017 & $01 / 04 / 1971$ & não consta & FCTH/DAEE-SP & Sim \\
\hline 2345067 & $01 / 08 / 1933$ & não consta & ANA & Não \\
\hline 2345175 & $01 / 10 / 1972$ & não consta & FCTH/DAEE-SP & Sim \\
\hline
\end{tabular}

As medidas de estatística aplicadas na série de 32 verões que auxiliaram o entendimento sobre a variabilidade da precipitação na área estudada foram: o total acumulado de dezembro, janeiro e fevereiro, o desvio da média e a frequiência das classes de valores de precipitação. Essa última foi representada pelo histograma gerado pela fórmula de Sturges (BOIN e ZAVATTINI, 2013). As respectivas fórmulas estão representadas a seguir:

- Total acumulado:

$$
\sum \text { dez, jan, fev }
$$

- Desvio da média:

$$
\mathrm{y}=\sum \mathrm{dez}, \mathrm{jan}, \mathrm{fev}-\overline{\mathrm{x}}
$$

- Fórmula de Sturges:

$$
\mathrm{k}=1+\left(3,3 \log _{\mathrm{n}}\right)
$$

Todos os valores resultantes estão expressos em milímetros de precipitação nos gráficos de 1 a 12 .

\section{Resultados e discussão}

$\mathrm{Na}$ Tabela 2 a seguir, estão sintetizadas as informações obtidas do Banco de Dados de Desastres Naturais e do Boletim Climanálise. Com base nesta tabela, pode-se afirmar que todos os eventos calamitosos analisados estiveram, principalmente, associados à atuação da Zona de Convergência do Atlântico Sul (ZCAS), a estruturação dos Vórtices Ciclônicos de Altos Níveis (VCAN), Alta da Bolívia (AB) e a passagem de frentes frias na região sudeste do Brasil.

Esses sistemas atmosféricos ocasionaram tanto chuvas moderadas, contínuas e fortes que resultaram em danos para o município de São Luiz do Paraitinga.

Danos como "Corte no fornecimento de energia e água", "Rompimento da rede de água e esgoto" e "Desabamentos" impedem o funcionamento de todos os setores do município, podendo até mesmo, o município atingir estado de calamidade pública.

Os dados das quatro estações analisadas apontam que, os totais pluviométricos dos 32 verões analisados vão desde $335 \mathrm{~mm}$ a $1334 \mathrm{~mm}$ de precipitação, o valor referente à mediana é de $602 \mathrm{~mm}$ de chuva. Com relação aos eventos de desastre, tem se que, 5 de 9 eventos ocorreram durante chuvas acima da média dos verões e, 4 de 9 eventos ocorreram durante chuvas abaixo da média dos verões.

A análise dos histogramas (Gráficos 3, 6, 9 e 12) aponta que, apesar de a maioria dos eventos terem ocorrido em verões com chuvas acima da média, esses volumes de precipitação são frequentes para o local.

Em decorrência dos fatos descritos anteriormente, destaca-se a importância de ações que visem o aumento da resiliência do município de São Luiz do Paraitinga, evitando assim, os danos de origem meteorológica, climática e hidrológica. 
Tabela 3. Informações sobre os eventos calamitosos.

\begin{tabular}{|c|c|c|c|c|c|c|}
\hline Verão & Data & Sistemas Atmosféricos & Fenômeno & Danos & $\begin{array}{l}\text { Total de } \\
\text { danos }\end{array}$ & $\begin{array}{l}\text { Total de } \\
\text { Vítimas }\end{array}$ \\
\hline \multirow{3}{*}{$2003 / 2004$} & \multirow{3}{*}{ 24/fev/04 } & \multirow{3}{*}{$\begin{array}{l}\text { Avanço das frentes frias e } \\
\text { dois episódios de ZCAS }\end{array}$} & \multirow{3}{*}{ Chuvas Fortes } & Deslizamento de terra; & \multirow{3}{*}{ Sem dados } & \multirow{3}{*}{ Sem dados } \\
\hline & & & & Queda de muro; & & \\
\hline & & & & $\begin{array}{l}\text { Desabamentos/Rachadura/Danos em } \\
\text { Imóveis. }\end{array}$ & & \\
\hline $2004 / 2005$ & 24/jan/05 & $\begin{array}{l}\text { Atuação de sistemas frontais, } \\
\text { a configuração de um } \\
\text { episódio de ZCAS e o } \\
\text { desenvolvimento de áreas de } \\
\text { instabilidade. }\end{array}$ & $\begin{array}{l}\text { Frente fria e chuvas } \\
\text { contínuas }\end{array}$ & $\begin{array}{c}\text { Desalojado(s), Transbordamento de Rios e } \\
\text { Córregos, Inundações Graduais. }\end{array}$ & Sem dados & Sem dados \\
\hline \multirow{5}{*}{$2005 / 2006$} & \multirow[b]{2}{*}{$12 / \mathrm{fev} / 06$} & \multirow{5}{*}{ Dois episódios de ZCAS. } & \multirow{2}{*}{$\begin{array}{l}\text { Frente fria/chuvas } \\
\text { contínuas }\end{array}$} & Deslizamento de terra; & \multirow[b]{2}{*}{ Sem dados } & \multirow[b]{2}{*}{ Sem dados } \\
\hline & & & & $\begin{array}{l}\text { Congestionamento/Interdição de Via } \\
\text { Pública }\end{array}$ & & \\
\hline & \multirow{3}{*}{ 22/fev/06 } & & \multirow{3}{*}{ Chuvas Fortes } & Desabrigado(s); & \multirow{3}{*}{ Sem dados } & \multirow{3}{*}{ Sem dado } \\
\hline & & & & Deslizamento de terra; & & \\
\hline & & & & $\begin{array}{c}\text { Desabamentos/Rachadura/Danos em } \\
\text { Imóveis }\end{array}$ & & \\
\hline \multirow{4}{*}{$2006 / 2007$} & \multirow[t]{2}{*}{ 26/dez/06 } & \multirow{4}{*}{$\begin{array}{l}\text { Quatro episódios de ZCAS, } \\
\text { atuação de quatro frentes } \\
\text { frias, associados a ciclones } \\
\text { extratropicais. }\end{array}$} & \multirow{2}{*}{ Chuvas fortes } & $\begin{array}{l}\text { Congestionamento/Interdição de Via } \\
\text { Pública; }\end{array}$ & \multirow{2}{*}{ Sem dados } & \multirow[t]{2}{*}{ Sem dados } \\
\hline & & & & Escorregamento de Encosta. & & \\
\hline & \multirow[b]{2}{*}{ 03/jan/07 } & & \multirow[b]{2}{*}{$\begin{array}{l}\text { Frente fria/chuvas } \\
\text { contínuas }\end{array}$} & Desalojados; & \multirow[b]{2}{*}{ Sem dados } & \multirow[b]{2}{*}{ Sem dados } \\
\hline & & & & $\begin{array}{l}\text { Desabamentos/Rachadura/Danos em } \\
\text { Imóveis. }\end{array}$ & & \\
\hline \multirow{4}{*}{$2007 / 2008$} & \multirow{4}{*}{ 03/jan/08 } & \multirow{4}{*}{$\begin{array}{l}\text { Um sistema frontal e três } \\
\text { episódios de ZCAS. }\end{array}$} & \multirow{4}{*}{ Chuvas fortes } & Desalojado(s); & \multirow{4}{*}{ Sem dados } & \multirow{4}{*}{ Sem dados } \\
\hline & & & & Transbordamento de Rios e Córregos; & & \\
\hline & & & & Inundações Graduais; & & \\
\hline & & & & Alagamentos; & & \\
\hline
\end{tabular}


Desabamentos/Rachadura/Danos em Imóveis.

\begin{tabular}{|c|c|c|c|c|c|c|}
\hline \multirow{5}{*}{$2008 / 2009$} & 21/dez/08 & \multirow{5}{*}{$\begin{array}{l}\text { Atuação da ZCAS com o } \\
\text { posicionamento dos VCAN's }\end{array}$} & $\begin{array}{c}\text { Ventos } \\
\text { fortes/vendaval; } \\
\text { Chuvas fortes }\end{array}$ & $\begin{array}{l}\text { Transbordamento de Rios e Córregos, } \\
\text { Inundações Graduais, } \\
\text { Desabamentos/Rachadura/Danos em } \\
\text { Imóveis }\end{array}$ & Sem dados & Sem dados \\
\hline & \multirow{4}{*}{ 15/fev/09 } & & \multirow{4}{*}{ Chuvas fortes } & Desabrigado(s); & \multirow{4}{*}{97} & \multirow{4}{*}{72} \\
\hline & & & & Desalojado(s); & & \\
\hline & & & & Deslizamento de terra; & & \\
\hline & & & & $\begin{array}{l}\text { Desabamentos/Rachadura/Danos em } \\
\text { Imóveis. }\end{array}$ & & \\
\hline \multirow{15}{*}{$2009 / 2010$} & \multirow{6}{*}{ 08/dez/09 } & \multirow{15}{*}{$\begin{array}{l}\text { Atuação da ZCAS, o } \\
\text { aumento da convergência de } \\
\text { umidade no setor central do } \\
\text { Brasil, reforçada pela } \\
\text { formação de um centro de } \\
\text { baixa pressão adjacente à } \\
\text { costa e pelo escoamento } \\
\text { associado à Alta da Bolívia e } \\
\text { aos vórtices ciclônicos. }\end{array}$} & \multirow{6}{*}{$\begin{array}{l}\text { Chuvas fortes, } \\
\text { Chuvas moderadas }\end{array}$} & Desalojados. & \multirow{6}{*}{17} & \multirow{6}{*}{ Sem dados } \\
\hline & & & & Queda de Árvores, & & \\
\hline & & & & Transbordamento de Rios e Córregos; & & \\
\hline & & & & Deslizamento de terra; & & \\
\hline & & & & $\begin{array}{l}\text { Desabamentos/Rachadura/Danos em } \\
\text { Imóveis; }\end{array}$ & & \\
\hline & & & & $\begin{array}{l}\text { Congestionamento/Interdição de Via } \\
\text { Pública }\end{array}$ & & \\
\hline & \multirow{4}{*}{ 09/dez/09 } & & \multirow{2}{*}{$\begin{array}{l}\text { Frente Fria/Chuvas } \\
\text { Contínuas; }\end{array}$} & Desalojado(s); & \multirow{4}{*}{ Sem dados } & \multirow{4}{*}{ Sem dados } \\
\hline & & & & Transbordamento de Rios e Córregos; & & \\
\hline & & & \multirow[b]{2}{*}{ Chuvas Moderadas } & Inundações Graduais; & & \\
\hline & & & & $\begin{array}{l}\text { Desabamentos/Rachadura/Danos em } \\
\text { Imóveis }\end{array}$ & & \\
\hline & \multirow{5}{*}{ 10/dez/09 } & & \multirow{2}{*}{$\begin{array}{l}\text { Frente fria/chuvas } \\
\text { contínuas; }\end{array}$} & Desalojado(s); & \multirow{5}{*}{ Sem dados } & \multirow{5}{*}{ Sem dados } \\
\hline & & & & Transbordamento de Rios e Córregos; & & \\
\hline & & & \multirow{3}{*}{ Chuvas moderadas } & Inundações Graduais & & \\
\hline & & & & Deslizamento de terra; & & \\
\hline & & & & Queda de Muro; & & \\
\hline
\end{tabular}




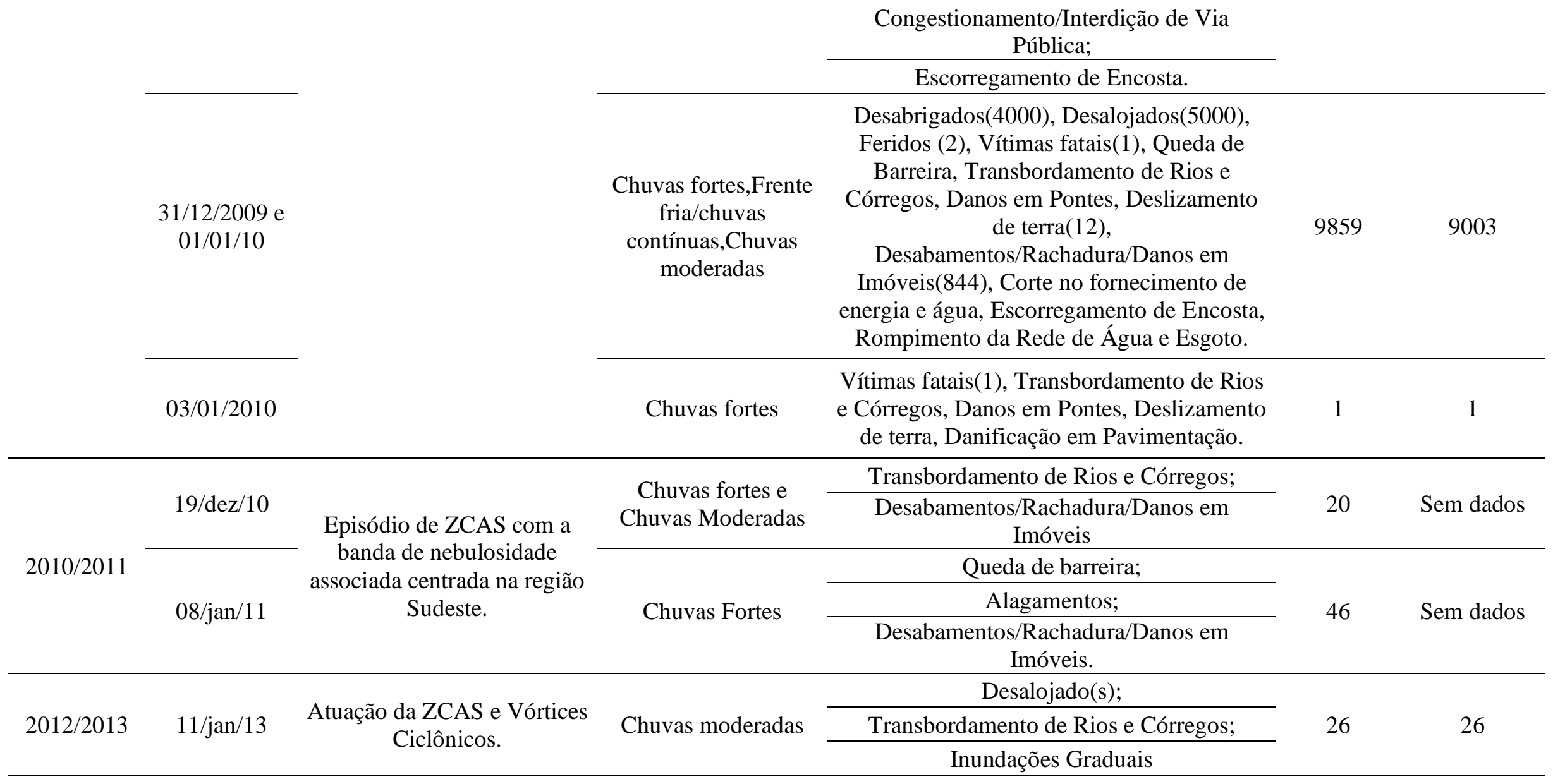




\section{Climatologia de precipitação}

\section{Medidas Estatísticas da Estação 02345017}

A Figura 3 apresenta o total de precipitação acumulado no período chuvoso (verão) da estação pluviométrica 02345017. Nota-se uma ampla variabilidade pluviométrica do semestre chuvoso com destaque para os períodos de 1995/1996, com
$790 \mathrm{~mm}$ acumulados, 1999/2000, com $828 \mathrm{~mm}$, e os anos de 2009/2010 e 2010/2011, com acumulados pluviométricos de $815 \mathrm{~mm}$ e $839 \mathrm{~mm}$, respectivamente. Os verões que apresentaram os totais pluviométricos mais reduzidos foram em 1997/1998, 2004/2005 e 2013/2014 com valores de $356 \mathrm{~mm}, 361 \mathrm{~mm}$ e $348 \mathrm{~mm}$, respectivamente.

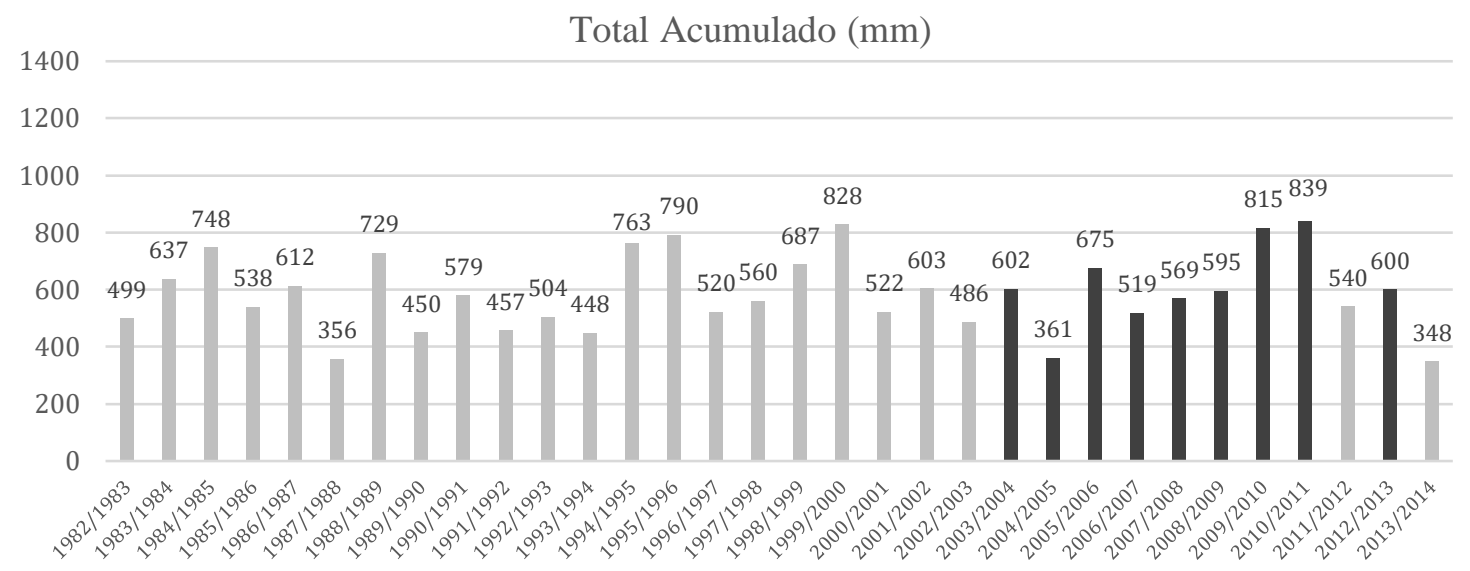

Figura 3. Total acumulado referente à estação 02345017, 32 verões. Fonte: Horta, 2017.

Os desvios da média referentes à estação pluviométrica 02345017 revelaram que os anos de 2009/2010 e 2010/2011 foram excepcionais, somando $228 \mathrm{~mm}$ e $235 \mathrm{~mm}$, respectivamente. Todavia, notou-se que os desvios negativos de precipitação foram registrados nos verões de 1987/1988, 2004/2005 e 2013/2014, com valores de $230 \mathrm{~mm}, 226 \mathrm{~mm}$ e $239 \mathrm{~mm}$, respectivamente (Figura 4).

\section{Desvio da média (mm)}

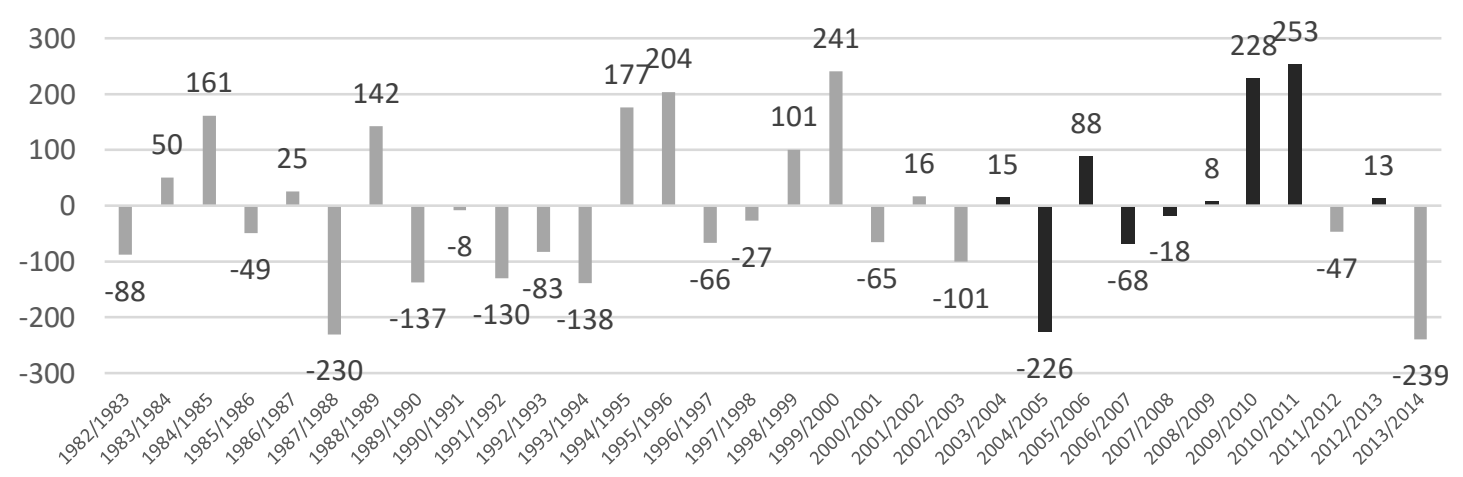

Figura 4. Desvio da média referente à estação 02345017, 32 verões. Fonte: Horta, 2017.

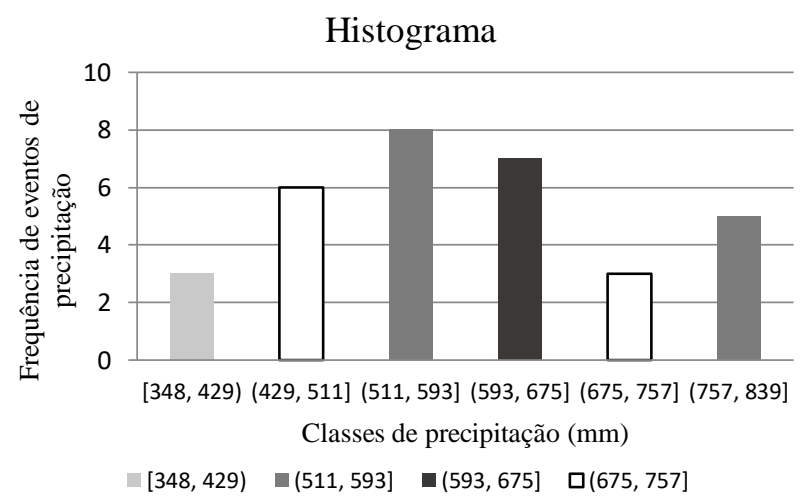

Figura 5. Histograma referente à estação 02345017, 32 verões. Fonte: Horta, 2017.

A partir do histograma apresentado na Figura 5 observa-se que a maior frequência de ocorrências de desastres (4 ocorrências) concentrase no terceiro maior valor de precipitação (de 593 $\mathrm{mm}$ a $675 \mathrm{~mm}$ ), que dentro dos 32 verões analisados ocorreu 7 vezes. Essa classe de eventos apresenta valores de precipitação acima da média de $587 \mathrm{~mm}$.

Medidas Estatísticas da Estação 02345065 
Observou-se na Figura 6 que na série temporal dos acumulados pluviométricos na estação 02345065 tais valores foram mais elevados em comparação com a estação anterior. No período em destaque, notam-se totais precipitados acima de
$900 \mathrm{~mm}$ no verão de 2009/2010. Entretanto, o período de 2004/2005, apresentou valores reduzidos, em consonância a estação 02345017 , com $465 \mathrm{~mm}$.

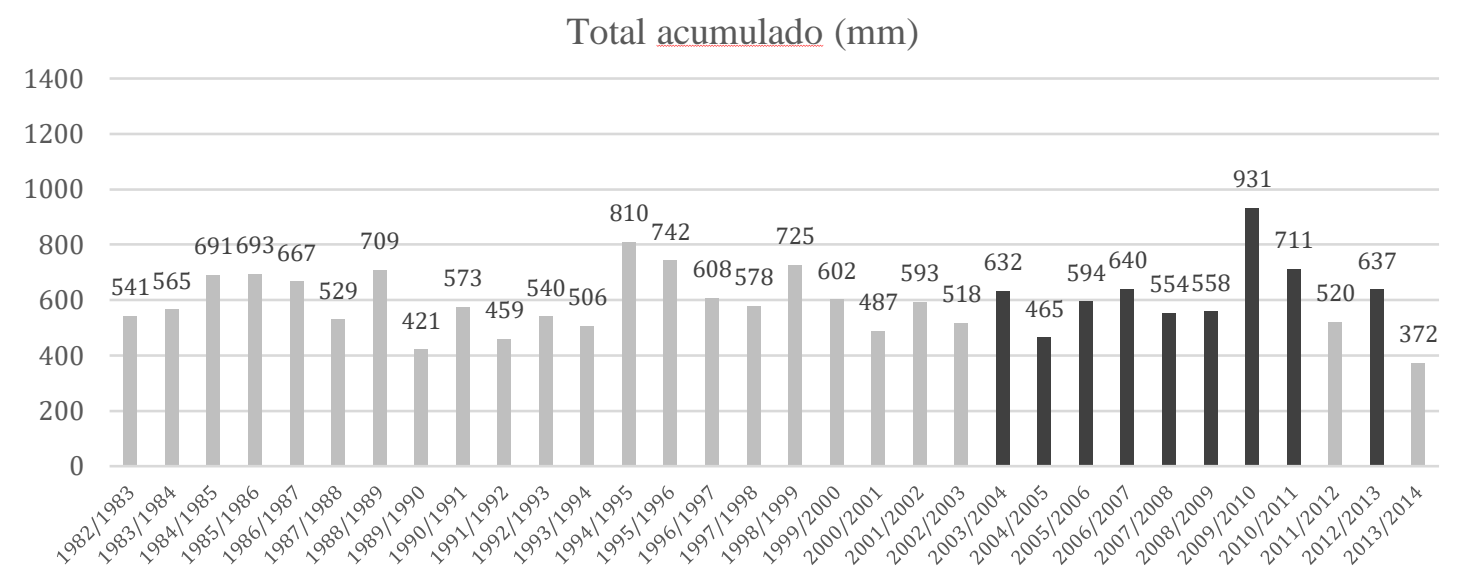

Figura 6. Total acumulado referente à estação 02345065, 32 verões. Fonte: Horta, 2017.

O desvio da média no ano de 2009/2010 destacou-se como o maior registro acumulado em toda a série temporal com 332 mm. Já o verão de 2013/2014 revelou o registro negativo excepcional de $227 \mathrm{~mm}$, em relação a média da série histórica.

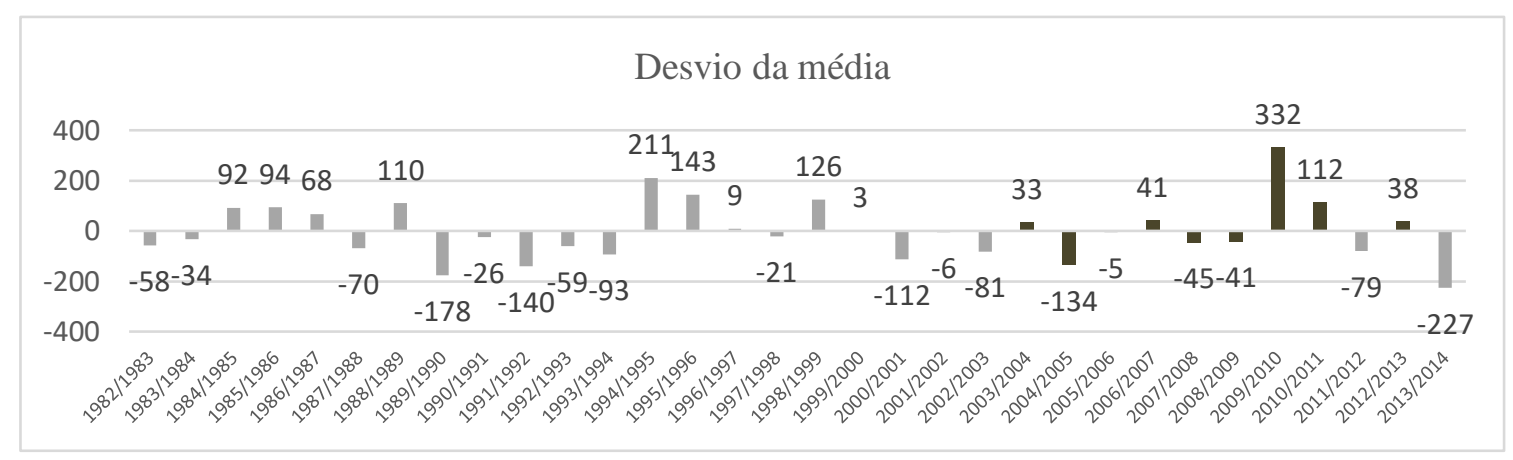

Figura 7. Desvio da média referente à estação 02345065, 32 verões. Fonte: Horta, 2017.

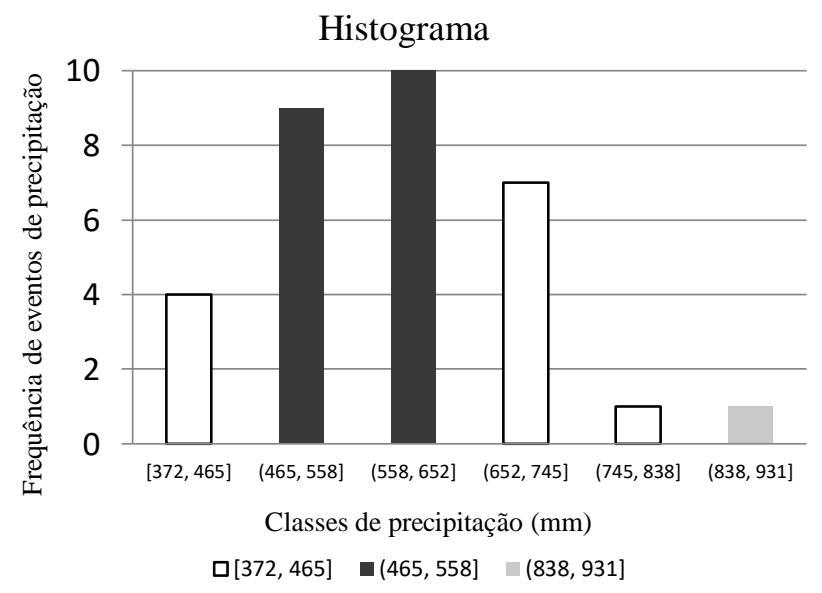

Figura 8. Histograma referente à estação 02345065, 32 verões. Fonte: Horta, 2017.

Os dados do histograma representado na Figura 8 demonstram que a maior quantidade de Horta, I.T.L.G., Neves, G Z. de F. ocorrências de desastres (4 ocorrências) concentrase na classe de precipitação de $558 \mathrm{~mm}$ a $652 \mathrm{~mm}$, dentro da média de $599 \mathrm{~mm}$. Essa classe, por sua vez representa 10 verões no ínterim de 32 verões analisados, sendo a maior representatividade da série histórica.

\section{Medidas Estatísticas da Estação 02345067}

Com relação a estação pluviométrica 02345067 , observou-se uma variabilidade ainda mais acentuada e recorrentes flutuações dos totais pluviométricos dos verões analisados. Notou-se que os anos de 1984/1985, 1995/1996 e os anos de 2008/2009 e 2009/2010, apresentaram totais pluviométricos de $1252 \mathrm{~mm}, 1334 \mathrm{~mm}, 1184 \mathrm{~mm}$ e $1098 \mathrm{~mm}$, respectivamente. Os verões com totais pluviométricos reduzidos foram identificados em 
1983/1984, 1989/1990 e 2013/2014, com os respectivos valores de $459 \mathrm{~mm}, 438 \mathrm{~mm}$ e $435 \mathrm{~mm}$, o que evidencia a recorrência interdecadal de totais pluviométricos reduzidos dentro do período chuvoso (Figura 9).

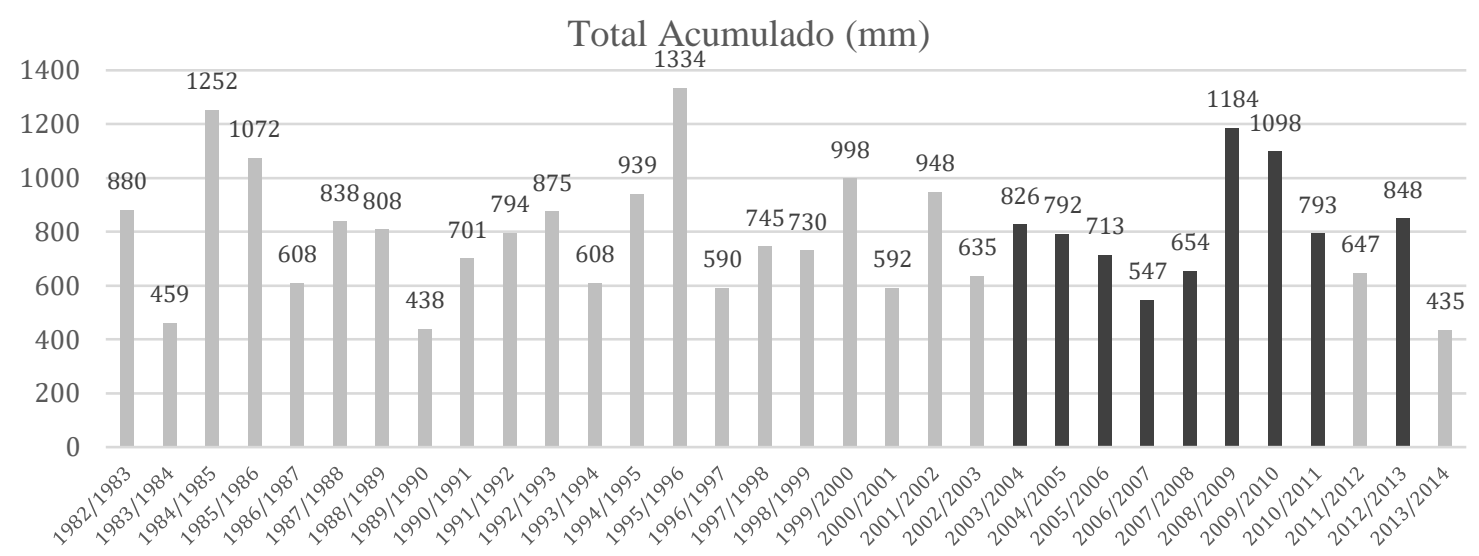

Figura 9.Total acumulado referente à estação 02345067, 32 verões. Fonte: Horta, 2017.

A Figura 10 apresenta os desvios padronizados de precipitação a fim de corroborar com os dados apresentados na ilustração anterior. Notou-se que o período de 1995/1996 apresentou um desvio positivo em relação a média de $541 \mathrm{~mm}$. No período de 2003/2004 até 2012/2013, destacaram-se os verões de 2008/2009 e 2009/2010, com registros positivos de $391 \mathrm{~mm}$ e $305 \mathrm{~mm}$, respectivamente.

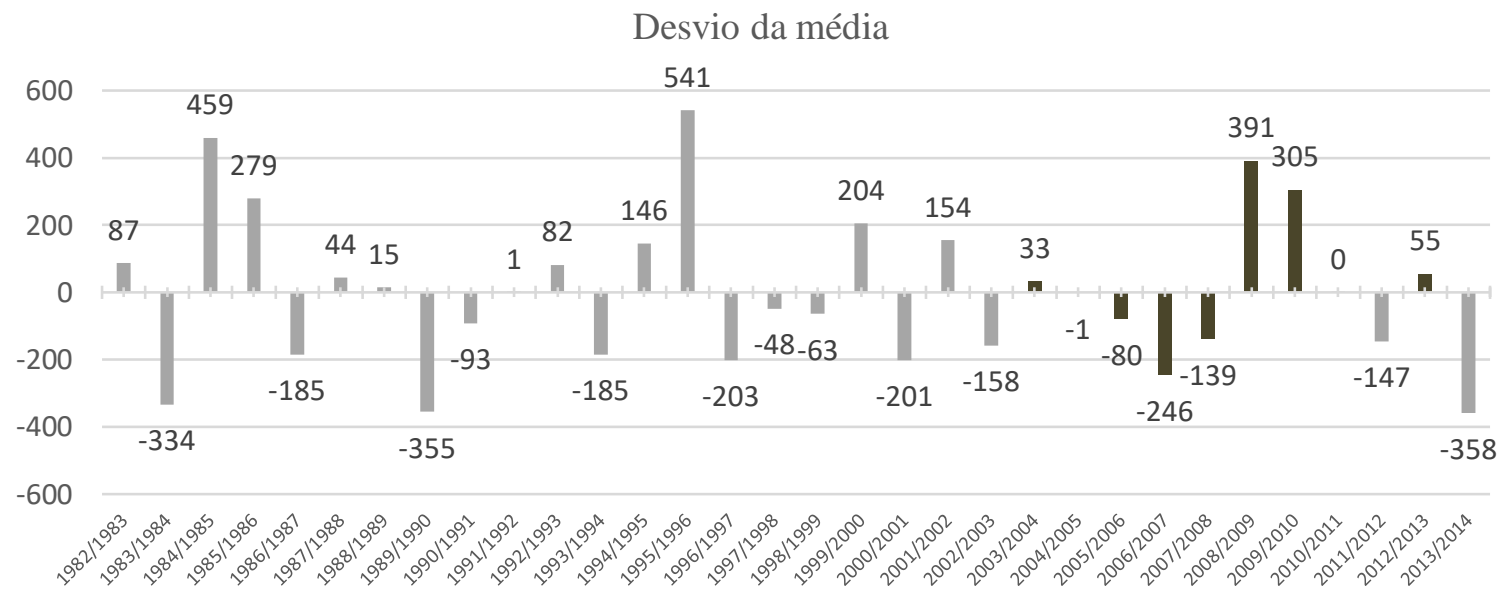

Figura 10. Desvio da média referente à estação 02345067, 32 verões. Fonte: Horta, 2017.

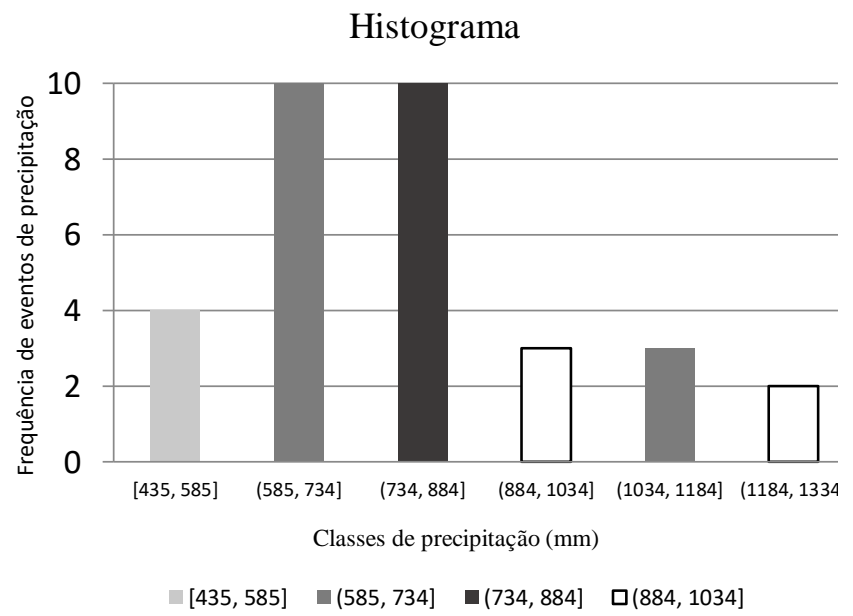

Figura 11. Histograma referente à estação 02345067, 32 verões. Fonte: Horta, 2017
Os dados do histograma apresentado na Figura 11 mostram que a maior ocorrência de desastres concentra-se durante eventos de precipitação dentro da média $(793 \mathrm{~mm})$, sendo também a classe de valor de precipitação que mais ocorreu durante a série histórica (10 vezes)

\section{Medidas Estatísticas da Estação 02345175}

A estação pluviométrica 02345175, em comparação com as demais citadas, foi a que apresentou os menores valores pluviométricos acumulados da série temporal. Para os anos em destaque na presente pesquisa, notou-se que os verões de 2005/2006, 2009/2010 e 2010/2011 apresentaram os totais pluviométricos mais 
significativos, com os respectivos registros de 675 $\mathrm{mm}, 815 \mathrm{~mm}$ e $839 \mathrm{~mm}$ (Figura 12).

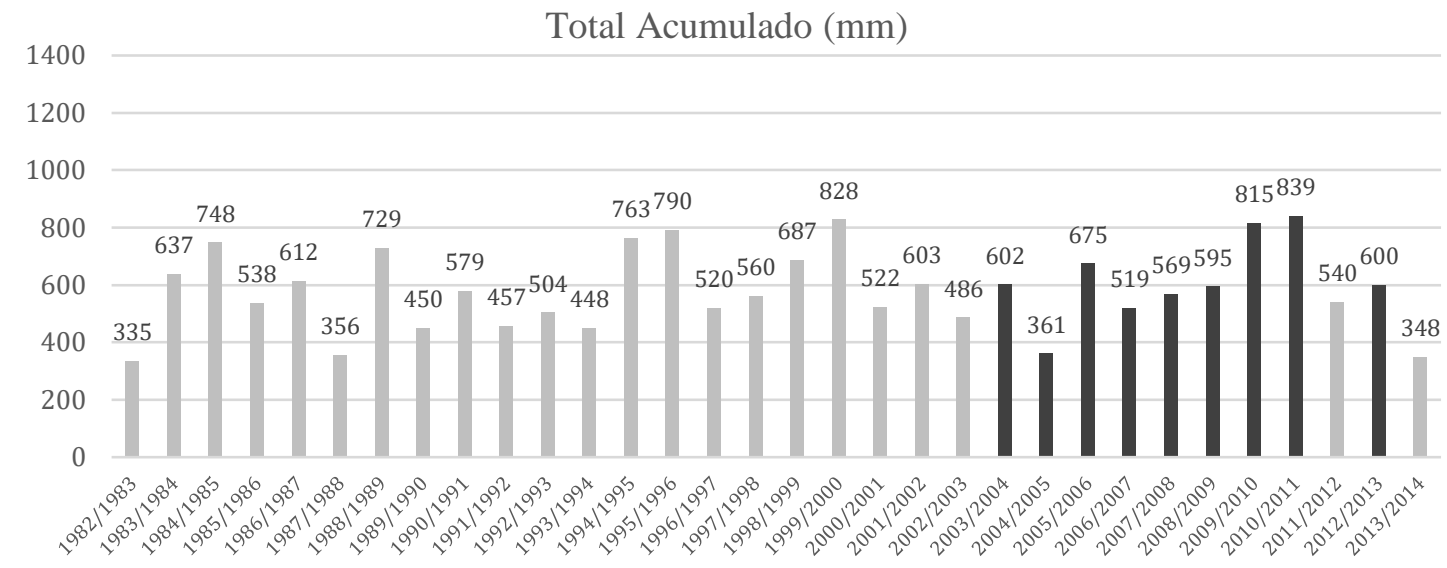

Figura 12. Total acumulado referente à estação 02345175, 32 verões. Fonte: Horta, 2017.

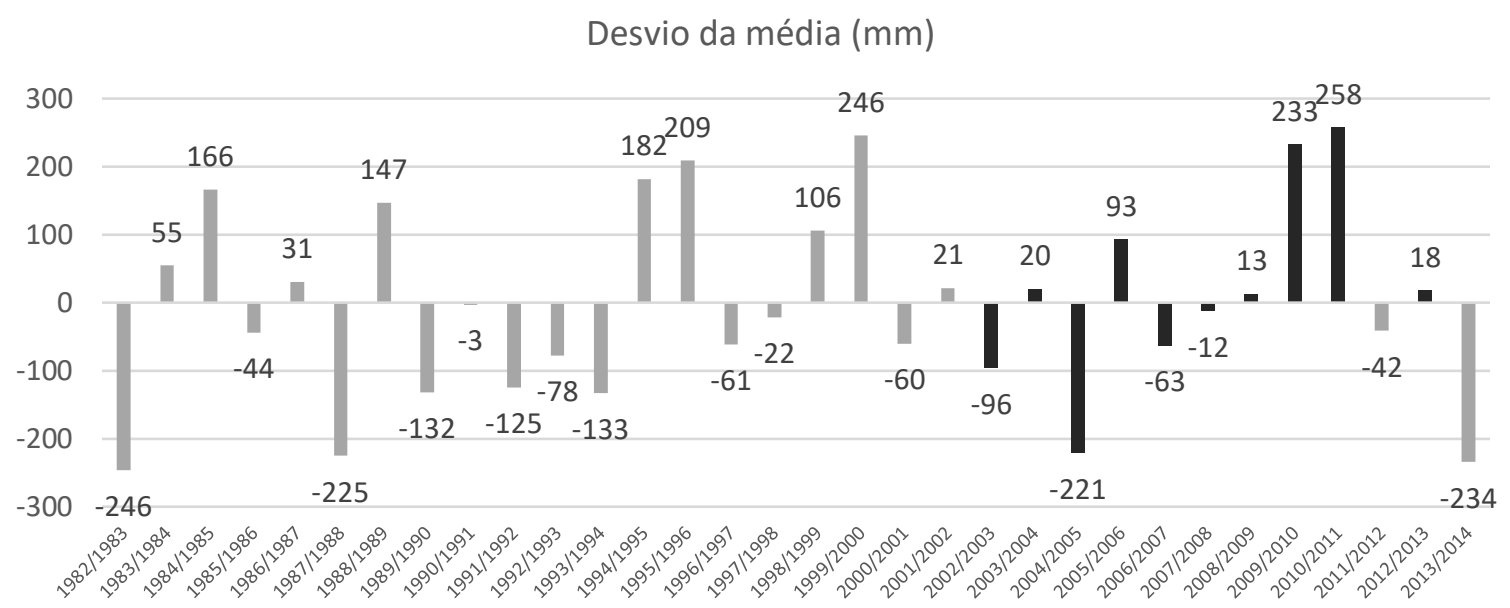

Figura 13. Desvio da média referente à estação 02345175, 32 verões. Fonte: Horta, 2017.

Destacam-se os períodos recorrentes com desvios de precipitação positivos e negativos, em relação à média da série histórica do posto 02345175. Em relação aos desvios positivos, notou-se que os anos de 1995/1996, com $209 \mathrm{~mm}$, 1999/2000 com valores de $246 \mathrm{~mm}$, e os verões consecutivos de 2009/2010 e 2010/2011, com registros de $233 \mathrm{~mm}$ e $258 \mathrm{~mm}$, respectivamente. Entretanto, os valores negativos em relação a média chamaram a atenção os verões de 1982/1983, 1987/1988, 2004/2005 e 2013/2014, todos estes com totais inferiores acima de $200 \mathrm{~mm}$ (Figura 13).

Os dados do histograma apresentado na Figura 14 demonstram que a maior quantidade de ocorrências de desastres (4 ocorrências) concentram-se na classe de valores de $587 \mathrm{~mm}$ a $671 \mathrm{~mm}$, que são acima da média $(582 \mathrm{~mm})$. No entanto, essa classe foi a segunda maior ocorrência dentro dos 32 verões analisados (6 verões).

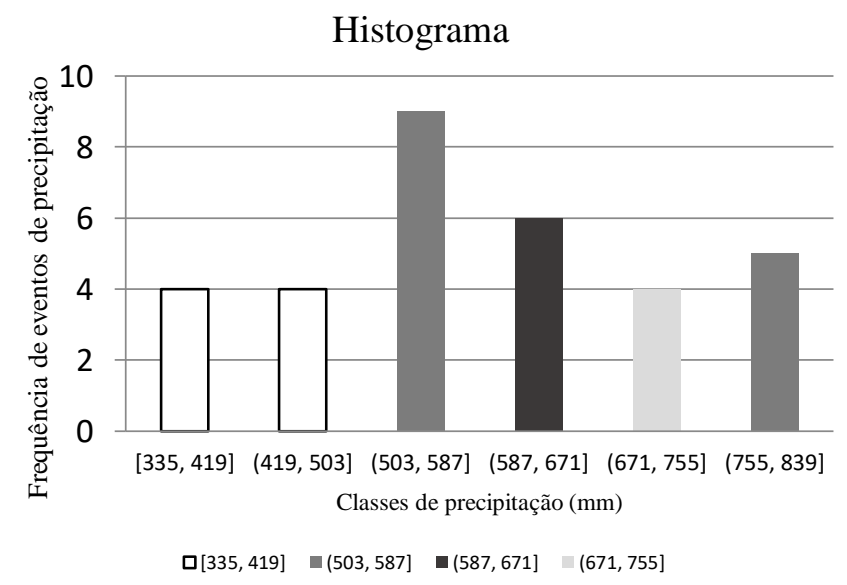

\section{Conclusões}

A partir da metodologia aplicada foi possível inferir que o município de São Luiz do Paraitinga - SP sofre com os impactos pluviais há mais de uma década. Destaca-se aqui que o Banco de Dados de Desastres Naturais do IPMet não tem 
registros dos impactos ocorridos antes de 2004 para o município de São Luiz do Paraitinga. O que não significa que as chuvas não causaram nenhum impacto antes dessa data.

Os resultados da estatística descritiva demonstraram que a maioria dos eventos ocorreram sob precipitação dentro da média ou acima da média e, tais valores de chuva são considerados recorrentes para o recorte temporal em questão (DEZ/JAN/FEV). O cruzamento das informações sobre os sistemas atmosféricos atuantes durante a ocorrência desses eventos permitiu constatar que, majoritariamente tais eventos ocorreram sob a atuação da ZCAS, frentes frias e Vórtices Ciclônicos.

Em consonância com a literatura apresentada constatou-se que a cidade de São Luiz do Paraitinga estabeleceu-se numa região de influência da ZCAS e, isso, em conjunto com as feições geomorfológicas denominadas de "mares de morros" e com o histórico de uso e ocupação do solo por eucalipto e pastagem compõem fatores que podem ocasionar eventos calamitosos, deflagrados por chuvas fortes.

Essa predisposição apresentada no estudo somada ao fato de que a cidade não possuía até 2010 uma Defesa Civil ou um plano de ações para a redução de riscos e desastres fez aumentar a vulnerabilidade da população e a gravidade dos impactos sofridos.

A análise aqui realizada a partir dos dados demonstrados pode servir como base para outros estudos da mesma temática como forma de melhorar o estado da arte da ciência ou, até mesmo servir como base para a justificativa de políticas que visem à proteção e defesa da população luizense.

\section{Agradecimentos}

Os autores agradecem o financiamento do Conselho Nacional de Desenvolvimento Científico e Tecnológico (CNPq) para o desenvolvimento da pesquisa.

\section{Referências}

ANA. Agência Nacional De Águas., 2009. Inventário das estações pluviométricas. 2.ed. Brasília: ANA; SGH.

ATLAS brasileiro de desastres naturais: 1991 a 2012., 2013. 2.ed. rev. ampl. UFSC/CEPED,Florianópolis.

Boin, M.N.,Zavattini, J.A., 2013. Climatologia geográfica - teoria e prática de pesquisa.Alínea,Campinas.

CLIMANÁLISE., 1986. Boletim de Monitoramento e Análise Climática. Cachoeira
Paulista, SP, Brasil, INPE/CPTEC. Publicação Mensal. ISSN 0103-0019 CDU-555.5

Corsi, A.C.; Azevedo, P.B.M.; Gramani, M.F., 2012. Valoração de danos decorrente da inundação em São Luiz do Paraitinga. Revista de Gestão Ambiental e Sustentabilidade [enlinea], v.1, n.2. Disponível:http://www.redalyc.org/articulo.oa? $\mathrm{id}=471647097006$. Acesso: 15 mai. 2017.

EM-DAT.The

InternationalDisasterDatabase.Centre for

ResearchontheEpidemiology of

Disasters.Disponível:https://www.emdat.be/.

Acesso:8mar. 2017.

EIRD (Estratégia Internacional de Redução de Desastres)., 2004. Organização das Nações Unidas.Glosario de La Estrategia. Disponível: http://www.eird.org/esp/terminologiaesp.htm. Acesso: 27 nov. 2018.

HIDROWEB: sistemas de informações hidrológicas. Séries históricas. Disponível: <http://www.snirh.gov.br/hidroweb/publico/ap resentacao.jsf . Acesso: 15 out. 2015.

Horta, I.T.L.G., 2017. Análise de impactos pluviais em São Luiz do Paraitinga - SP/Brasil. 2017. Dissertação (Mestrado). São Carlos, USP.

IBGE. Instituto Brasileiro De Geografia E Estatística., 2010. Malha dos setores censitários. Disponível: ftp://geoftp.ibge.gov.br/recortes_para_fins_est atisticos/malha_de_setores_censitarios/censo_ 2010/base_de_faces_de_logradouros. Acesso: 14 set. 2016.

Kron W, Steuer M, Löw P, Wirtz A., 2012.How to dealproperlywith a natural catastrophedatabase - analysis of floodlosses. Nat. Hazards Earth Syst. Sci. 12: 535-550.

Marcelino, E.V., 2008. Desastres naturais e geotecnologias: conceitos básicos. INPE,São José dos Campos.

Monteiro, C.A.F. Clima e excepcionalismo conjecturas sobre o desempenho da atmosfera como fenômeno geográfico. Florianópolis: Ed.UFSC, 1991.

Moura, C.A., Jimenez-Rueda, J.R., Martins Coelho, J.O., 2006. O Processo pedogenético no domínio tropical atlântico - o exemplo do Vale do Paraíba do Sul/SP. In: Simpósio Nacional De Geomorfologia / Regional Conference On GeomorphologY, 4., Goiânia. Anais... Meghalaya: InternationalAssociation of Geomorphologists.

Narváez L., Lavell A., Ortega G.P., 2009. La gestióndelriesgo de desastres: un enfoque basadoenprocesos. San Isidro: Secretaría General de laComunidad Andina. 
OPAS. Organização Pan-Americana da Saúde. Ministério da Saúde., 2015. Desastres Naturais e Saúde no Brasil. Brasília, DF: OPAS, Ministério da Saúde. 56p.

Pellegrina, G.J., 2011. Proposta de um procedimento metodológico para o estudo de problemas geoambientais com base em banco dedados de eventos atmosféricos severos. 2011. Dissertação (Mestrado). Bauru, UNESP.
Quadro, M.F.L.,Pezzi, L.P., Rosa, E.B.O., 2006.Climanálise e o monitoramento da ZCAS nos últimos 30 anos. Revista Climanálise, ano 3 ,

n.1.Disponível:http://climanalise.cptec.inpe.br/ $\sim$ rclimanl/revista/pdf/30anos/quadroetal.pdf. Acesso:6 jun. 2017.

WMO. World MeteorologicalOrganization. Meteoterm.

Disponível:http://wmo.multitranstms.com/Mult iTransWeb/Web.mvc.Acesso:05 ago. 2016. 